\title{
Sheep Mange Mites and Lice: Prevalence and Risk Factors in Asella and its Surroundings, South Eastern Ethiopia
}

\section{Desalegn Deferes ${ }^{1}$ and Minda Asfaw Geresu*}

${ }^{1}$ Lemu Bilbilo District Livestock and Fisheries Resource and Development Office, Arsi, Ethiopia

${ }^{2}$ School of Agriculture, Animal and Range Sciences Course Team, Madda Walabu University, Bale-Robe, Ethiopia

\begin{abstract}
A cross-sectional study was conducted to determine the prevalence and risk factors for sheep mange mites and lice infestation in Asella and its surroundings of south eastern Ethiopia, from November, 2009 to April, 2010. The study revealed that $212(55.21 \%)$ of the 384 sheep examined were infested with mange mites or lice in the study area. A higher prevalence of pediculosis $(49.5 \%)$ was observed compared to mange mite infestation which was rarely observed with prevalence rate of $5.72 \%$. Mange mites genera identified in the present study were Sarcoptes $(2.6 \%)$, Psoroptes $(2.3 \%)$, Chorioptes $(0.8 \%)$ while no Demodex was identified in the study settings of sheep. Pertaining to lice infestation, Bovicola ovis (36.7\%) and Linognathus ovillus (16.9\%) were the only identified species of lice. A negative association $(p>0.05)$ of mange mites and lice infestation was observed among the sex groups while only lice infestation was positively associated $(p<0.05)$ with the age groups of sheep in the study environs. Concerning to body condition scores, a chi-square analysis revealed that lice infestation was highly positively associated $(p=0.000)$ with the covariates (different body condition score group) in which the highest prevalence of lice infestation was observed in sheep with poor body condition score (67.36\%). Nevertheless, mange mite infestation was negatively associated $(p>0.05)$ with different body condition scores as the statistical analysis revealed. The result of this study revealed that as an ever increasing threat of mange mite and lice infestation on overall sheep productivity and tanning industry in Ethiopia warrants urgent control intervention. Hence, to reduce mange mite and lice infestation prevalence and impact on the productivity and health status, planning of integrated control measures with sustainable veterinary services aiming at creating awareness about the importance and control of the ectoparasites for small ruminant's owners is recommended.
\end{abstract}

Keywords: Lice; Mange mites; Prevalence; Risk factors; Sheep; Asella

\section{Introduction}

Ethiopia with its greatest variation in climate and topography possesses one of the largest small ruminant populations in the world, which is kept extensively mostly by small holder farmers and adjacent to crop production [1-3]. The country is home to 23.6 million sheep [4], but the immense potential these numbers represent has yet to be realized due to a multitude of factors. Ectoparasites are very common and widely distributed in all agro-ecological zones in Ethiopia $[5,6]$. They are one of the major hindrances to the productivity of sheep in the country and infestation caused by the ectoparasites could lead to considerable economic losses to farmers due to loss of productivity, mortality, and skin diseases. Among the ectoparasites; lice, sheep keds, ticks, fleas and mange mites causes a great preslaughter defects responsible for downgrading and rejection of skins that confront the productivity of sheep [7]. About $35 \%$ of sheep and $56 \%$ of goat skin rejections in Ethiopia are attributed to ectoparasites [8] and all these established facts revealed that the ectoparasites pose serious economic losses to the farmer, the tanning industry and the country as a whole $[7,9]$.

Mange mites are common in Ethiopia and therefore are reported from many regions and different agro climates. Based on the reports so far, mange mites are most prevalent in four national regional states of Ethiopia namely, the Amhara, Oromia, Tigray and Southern Nation and Nationalities regional states [10-12]. In all reports, three genera of mites namely, Sarcoptes, Psoroptes and Demodex were reported to affect small ruminants. In addition to this, lice infestation in the country is the most frequently reported and the most important skin disease of small ruminants this is because lice are found to be the cause of cockle [13].
Various studies have been conducted to determine the prevalence of mange mites and lice infestation in various regions of Ethiopia. Among the three genera of mites, Sarcoptic scabiei var. caprae and Sarcoptic scabiei var. ovis have a wide geographic distribution in many goat and sheep rearing in arid and semi-arid areas of Ethiopia, and it is more commonly seen in goats than sheep. In Ethiopia, they are widely distributed in lowland mainly [10-12], low and midlands [7] as well as central midland part of the country [14]. Studies conducted by Kedir [15] in Tigray (30.32\%) and Fekadu et al. [12] in Southern Ethiopia $(57.6 \%)$ disclosed the highest prevalence of sarcoptic mites in sheep and goats in the country.

Concerning, mites of the genus Psoroptes that cause psoroptic mange in sheep and goats, its prevalence is found greater than in goats therefore, it causes greater damage in sheep than in goats [13] and recent studies depicted that Psoroptic mange is most common among small ruminants in lowland areas of north $[8,11]$ and South ecological zones in Ethiopia as reported by Yacob et al. [10] in central lowland of Oromia; by Sertse et al. [16] in midland and highlands of Amhara region, and [12] in lowland and midland areas in southern part of the

${ }^{*}$ Corresponding author: Minda Asfaw Geresu, School of Agriculture, Animal and Range Sciences Course Team, Madda Walabu University, Bale-Robe, Ethiopia, Tel: +251910431505; E-mail: minda.asfaw@gmail.com

Received July 28, 2016; Accepted August 04, 2016; Published August 09, 2016

Citation: Deferes D, Geresu MA (2016) Sheep Mange Mites and Lice: Prevalence and Risk Factors in Asella and its Surroundings, South Eastern Ethiopia. J Vet Sci Technol 7: 371. doi: 10.4172/2157-7579.1000371

Copyright: ( 2016 Deferes D, et al. This is an open-access article distributed under the terms of the Creative Commons Attribution License, which permits unrestricted use, distribution, and reproduction in any medium, provided the original author and source are credited. 
country. Demodectic mange has also been reported different authors in sheep (Demodex ovis) and goats (Demodex caprae) and it is distributed in different agro ecological zones of the country as the works of [10] in central lowland of Oromia region, [16] in midland and highlands of Amhara region and [12] in lowland and midland areas in southern part of the country revealed.

Nowadays, in addition to mange mite infestation, pediculosis is a serious health problem of small ruminants in Ethiopia which is caused by lice infestation and it is the most frequently reported and important skin disease of small ruminants this is because lice are found to be the cause of cockle. Studies conducted by Yacob, Mulugeta, Sertse, Hailu et al. $[10,11,17,18]$ reported different lice spp infestation in sheep from Wolaita Soddo, Tigray, Amhara regional state and Asella in the country respectively

Nevertheless all the above study revealed that as mange mite and lice infestation seriously devastating sheep production system and tanning industry in Ethiopia, there is paucity of published data (information) about the prevalence of mange mites and lice infestation in sheep production system in Arsi Zone in general and in Asella and its surroundings as the potential it has in particular. This scarcity of information on the presence and prevalence of mange mites and lice infestation in sheep production system of the study area may reflect a lack of resources for the ectoparasite surveillance and control in sheep production system or most of the work done there may be left unpublished (left on shelf). In addition, most of mange mites and lice infestation, remain undiagnosed and only diazinon spray or Ivermectin injection has been applied without considering the efficacy and management system and the farmers consider skin losses as normal and natural. Therefore, information on the prevalence and risk factors exposing to mange mite and lice infestation has to be studied in detail in order to apply control measures based on mass treatment or effective movement control.

Hence, this study was conducted: to determine the prevalence of mange mite and lice infestation in sheep in Asella and its surroundings and to assess the putative risk factors exposing to mange mite and lice infestation in the selected study area. Therefore, our study could be a foil for the paucity of information about the prevalence of mange mites and lice infestation and presumed risk factors exposing to the ectoparasite infestation in the sheep production system of the study area.

\section{Materials and Methods}

\section{Description of the study area}

The study was conducted in Asella town and its surrounding, Arsi Zone, Oromia Regional State. It is located at $175 \mathrm{~km}$ in south east of Ethiopia within $6^{\circ} 59-8^{\circ} 49^{\prime} \mathrm{N}$ latitude and $38^{\circ} 41^{\prime}-40^{\circ} 44^{\prime} \mathrm{E}$ longitude. Topographically, Asella is a high land area with altitude ranging from 1300 to 1350 meter above sea level and has annual rain fall of 2300 to $2400 \mathrm{~mm}$ [19]. Vegetation of the area changes with altitude and rainfall ranging from scattered trees and bushes to dense shrubs and bushes from the total land of $43 \%$ used for grazing, 35\% for cultivation $8.6 \%$ forest land, $10.7 \%$ pastureland. It is one of the highly populated areas in Ethiopia with estimated human population of 2,521,349 and livestock population of bovine-82,190; ovine-51,292; caprine-8,11,479; poultry-5, 62,915 and equine-22,055 [20,21].

\section{Study animals}

In our study, a total of 384 sheep of different age groups, both sexes and of local breeds coming to the Asella town Veterinary Clinic for veterinary services, were examined for the presence of mange mites and lice infestation. During sampling, history, age, sex, and body condition scores of each animal were recorded. The animals were grouped into two age categories, as young (up to one year) and adult (older than one year) as described by Steele and ESGPIP [22,23]. Age determination was made using owner's information and by dentition. Body condition scores were determined following the procedures documented by Steele and ESGPIP [22,23] for sampled animals as poor, medium and good classes following 1 up to 5 grading system.

\section{Study design and sample size determination}

A cross-sectional study design was conducted to determine the prevalence of mange mites and lice infestation in the selected study area and to identify the potential risk factors associated with the two ectoparasite infestations. A simple random sampling method was employed and the study animals were randomly selected and examination was conducted through visual inspection and palpation to detect the presence of skin lesion. The sample size was calculated according to Thrusfield [24] by considering 50\% expected prevalence (P), 95\% confidence interval (CI) $(\mathrm{Z}=1.96)$ with $5 \%$ desired absolute precision (d), using the formula $\mathrm{N}=(\mathrm{Z})^{2} \mathrm{P}(1-\mathrm{P}) / \mathrm{d}^{2}$. Hence, the calculated required sample size $(\mathrm{N})$ was 384 .

\section{Ectoparasites collection and identification}

After proper restraining, representative specimens were collected from infested and diseased animals. Ectoparasites (sheep keds, ticks, lice and fleas) either encountered on the skin surface or attached to the hair were collected manually from their sites of attachment. A coat brushing technique was applied to collect lice from host skin. Then the collected samples were placed in labeled universal bottles containing $70 \%$ ethanol and taken to the Parasitology Section, Laboratory of the Asella Regional Animal Health Diagnostic and Investigation Centre located in Asella town. In the laboratory, the ectoparasites were identified with the basis of their morphological structure using the recommendations of Urquhart et al. [25] and Wall and Shearer [26]. Further identification at species level was conducted using a stereomicroscope according to their key morphological structures for lice. In addition, skin scrapings for mange mites were collected from clinically suspected animals. This was made by clipping the hair around affected areas using scissors, scraping the edges of the lesion with the scalpel blades [25] until capillary blood oozing was evident. The scraped materials were transferred to a container containing $10 \%$ formalin and were taken for laboratory examination. Then in the laboratory, a few drops of $10 \%$ potassium hydroxide were added to the specimen, allowed to stand for 30 minutes, and examined under a light microscope at $40 \mathrm{x}$ magnification $[7,25]$. The mange mites were identified with the morphological keys of Urquhart et al. [25] and Kumsa et al. [26].

\section{Data analysis}

Data generated from the questionnaire survey and laboratory investigations were recorded and coded using Microsoft Excel spreadsheet (Microsoft Corporation) and analyzed using STATA version 11.0 for Windows (Stata Corp. College Station, TX, USA). The prevalence of pig mange mites and lice infestation was calculated as the number of positive samples divided by the total number of samples tested. To identify association of prevalence with the risk factors (sex, age and body condition scores) were computed by percentages and Pearson's chi-square $\left(\chi^{2}\right)$ test. In all cases $p<0.05$ was considered as statistically significant. 
Citation: Deferes D, Geresu MA (2016) Sheep Mange Mites and Lice: Prevalence and Risk Factors in Asella and its Surroundings, South Eastern Ethiopia. J Vet Sci Technol 7: 371. doi: 10.4172/2157-7579.1000371

Page 3 of 6

\section{Results}

\section{Overall prevalence of mange mite and lice infestation in sheep identified in this study}

Ectoparasitological data analysis revealed that 212 of 384 total sheep flock examined harbored either single or mixed infection. The overall prevalence of lice and mange mite infestation in the flock was $55.21 \%$. Of 384 total sheep examined, 22 sheep were infected by both mange and lice (mixed infection). The result signified that the higher prevalence of pediculosis (49.5\%) was observed in sheep in the study area. Nevertheless, mange mite infestation was rarely observed with prevalence rate of $5.72 \%$ as depicted in Table 1.

\section{Prevalence of species of mange mites and lice in the study area}

The three major genera of mange mites identified from the sampled sheep were Sarcoptes spp (2.6\%), Psoroptes spp (2.3\%) and Chorioptes spp $(0.8 \%)$ while no Demodex spp was found in the present study. Pertaining to the lice infestation, Bovicola ovis (B. ovis) (36.7\%) and Linognathus ovillus (L. ovillus) (16.9\%) were observed in this study. Sarcoptes spp (2.6\%) were the most relatively higher in prevalence among the mange mite species identified while the prevalence of $B$. ovis was higher when compared to L. ovillus among the lice infestation observed in this study (Table 2).

\section{A chi-square analysis of association of the putative risk factors with mange mite and lice infestation in sheep}

Prevalence of mange mite and lice infestation in sheep in relation to sex group: The prevalence of lice infestation in male sheep $(55.39 \%)$ was roughly the same with that of female sheep $(54.95 \%)$.
Furthermore, the prevalence of mange mite infestation in male (5.75\%) and female (6.06) sheep flocks was almost similar and the covariate (sex) was negatively associated with the prevalence of mange mite and lice infestation in flocks of sheep in the study area as illustrated in Tables 3-5.

Prevalence of mange mite and lice infestation with respect to the age group of the animal: A relatively higher prevalence of mange mites $(6.56 \%)$ and lice $(52.44 \%)$ infestations were found in adult animals in the study area when compared to young animals. Both young $(43.90 \%)$ and adult (52.44\%) sheep were highly infested by lice than mange mites. The prevalence of lice infestation was positively associated $\left(\chi^{2}\right.$ $=6.330 ; p<0.05$ ) with the putative covariate (age group) whereas the prevalence of mange mite infestation was not considerably associated ( $p>0.05$ ) with the putative risk factor (age group).

Prevalence of mange mite and lice in sheep by body condition scores: A relatively higher prevalence of mange mite infestation was found in animals with poor body condition score (6.94\%) than in animals with medium and good body condition score while the highest lice infestation was observed in animals with poor body condition score in relation to the animals with medium and good body condition score. The prevalence of lice infestation was highly significantly associated $\left(\chi^{2}=44.103 ; p=0.000\right)$ with the independent variable (body condition score) whereas the prevalence of mange mite infestation was negatively associated $(p>0.05)$ with the putative exposing risk factor (body condition score).

\section{Discussion}

The present study ascertained an overall prevalence of $55.21 \%$ of

\begin{tabular}{|c|c|c|c|}
\hline Ectoparasite & No. of sheep examined & No. of sheep found positive & Overall prevalence (\%) \\
\hline Mange & 384 & 5.72 \\
\hline Lice & 384 & 190 & 49.5 \\
\hline Total & 384 & 212 & 55.21 \\
\hline
\end{tabular}

Table 1: Total prevalence of lice and mange infection in sheep in Asella and its surroundings.

\begin{tabular}{|c|c|c|c|c|}
\hline \multicolumn{2}{|c|}{ Ectoparasite species } & No. of animals examined & No. of positive animals & Prevalence (\%) \\
\hline \multirow[t]{4}{*}{ Mange } & Sarcoptes & \multirow{4}{*}{384} & 10 & 2.6 \\
\hline & Psoroptes & & 9 & 2.3 \\
\hline & Chorioptes & & 3 & 0.8 \\
\hline & Demodex & & 0 & 0 \\
\hline \multirow[t]{2}{*}{ Lice } & Bovicola ovis & \multirow{2}{*}{384} & 141 & 36.7 \\
\hline & Linognathus ovillus & & 65 & 16.9 \\
\hline
\end{tabular}

Table 2: Prevalence of genera of mange and lice in Asella and its surroundings.

\begin{tabular}{|c|c|c|c|}
\hline Ectoparasite identified & \multicolumn{2}{|c|}{ Covariate (sex group) } \\
\hline & Male (N=139) & Female (N=245) \\
\hline & Prevalence (\%) & Prevalence (\%) \\
\hline Mange & 5.75 & 6.06 & $0.000(0.987)$ \\
\hline Lice & 55.39 & 54.95 \\
\hline
\end{tabular}

$\mathrm{N}$ : Number of animals examined

Table 3: Lice and mange infestation association with the sex groups in Asella and its surrounding.

\begin{tabular}{|c|c|c|c|}
\hline \multirow[t]{3}{*}{ Ectoparasite identified } & \multicolumn{2}{|c|}{ Covariate (age group) } & \multirow[t]{3}{*}{$x^{2}$ (p-value) } \\
\hline & Young (N=125) & Adult (N=259) & \\
\hline & Prevalence (\%) & Prevalence (\%) & \\
\hline $\begin{array}{l}\text { Mange } \\
\text { Lice }\end{array}$ & $\begin{array}{c}4.06 \\
43.90\end{array}$ & $\begin{array}{c}6.56 \\
52.44\end{array}$ & $\begin{array}{l}1.086(0.581) \\
6.330(0.042)\end{array}$ \\
\hline
\end{tabular}

$\mathrm{N}$ : Number of animals examined

Table 4: Prevalence of lice and mange mite infestation in relation to age groups in the selected study area. 


\begin{tabular}{|c|c|c|c|}
\hline Ectoparasite & \multicolumn{3}{|c|}{ Covariate (body condition score) } \\
\hline & $\begin{array}{c}\text { Poor BCS } \\
\text { N (\%) }\end{array}$ & $\begin{array}{c}\text { Medium BCS } \\
\text { N (\%) }\end{array}$ & $\begin{array}{c}\text { Good BCS } \\
\text { N (\%) }\end{array}$ \\
\hline Mange & $10(6.94)$ & $8(4.659)$ & $4(3.88)$ \\
\hline Lice & $97(67.36)$ & $80(46.51)$ & $13(19.12)$ \\
\hline Overall prevalence & $107(27.86)$ & $88(22.91)$ & $44.103\left(0.000^{* *}\right)$ \\
\hline
\end{tabular}

BCS: Body Condition Score; N: Number of positive animals sampled; **: Highly significantly associated

Table 5: Prevalence of lice and mange mite infestation by body condition score of animals in the study area.

mange mites and lice infestations revealing that the great importance and widespread occurrence of the two ectoparasites in sheep in Asella and its surroundings. This finding is in agreement with the previous reports of the ectoparasites prevalence in small ruminants from different parts of Ethiopia [7,16,27,28] and other countries of the world $[29,30]$. Nonetheless, the finding of the current study was higher than the prevalence reported in the Southern range land of Oromia as reported by Molu [31] and Takele [32], and Zeryehun and Tadesse [33] at Nekemte Veterinary Clinic, Northwest of Ethiopia. The higher infestation rate is most probably attributable to several important factors including conducive environment, malnutrition and poor husbandry systems, poor awareness of farmers and inadequate veterinary services in study settings $[3,34,35]$.

The prevalence of sheep lice (49.5\%) recorded in this study is higher than the reports of Kumsa et al. [7] in three agro-ecological zones in central Oromia (28.7\%), Sertse and Wossene [16] in the eastern part of Amhara region (39.5\%), Mulugeta [28] in south-eastern parts of Tigray (30.5\%) and Haffize [36] in central Ethiopia (2\%). Such variations in prevalence might arise from differences in agro-ecology, the season during which the study was conducted, the management and health care of sheep in the study areas and the sensitivity of the diagnostic techniques employed. Louse infestations may indicate some other underlying problems such as malnutrition and chronic diseases $[7,37]$.

Meanwhile, the current study sheep mange mite infestation (5.72\%) was relatively higher than the report of Tefera [38] in selected sites of Amhara regional state and Israel et al. [39] in Sodo Zuria district of southern Ethiopia. This study revealed that three genera of mange mites identified, namely, sarcoptes $(2.6 \%)$, chorioptes $(2.3 \%)$ and psoroptes $(0.8 \%)$ in the study area. These genera of mange mites have been commonly reported from different parts of Ethiopia [36,39-41]. A bit higher prevalence of Sarcoptes was observed in the present work which is in agreement with the report of Zeryehun and Tadesse [33] in sheep at Nekemte Veterinary Clinic of Northwest Ethiopia (2.5\%). The lesion of Sarcoptes scabiei var ovis in sheep was observed mostly around the ear, face and head areas and nodule formation was the characteristics lesion recorded. Kettle [42] observed that, sarcoptic mange if they occur in sheep in general they are frequently observed in sparsely haired parts.

Pertaining to lice infestation in Ethiopia, it is the most frequently reported and important skin disease of small ruminants this is because lice are found to be the cause of cockle. The present study established a higher prevalence of B. ovis (36.7\%) and L. ovillus (16.9\%). This finding is in agreement with the work of Asnake et al. [12] who reported $14.6 \%$ of L. ovillus and $36.1 \%$ of B. ovis of sheep in three agro-ecological districts of southern Ethiopia. However, the present finding is higher than the works of Yacob et al. [10] and Mulugeta et al. [11] in which $26.64 \%$ of B. ovis from Wolayta Sodo, and $15.3 \%$ of B. ovis and $27.9 \%$ of L. ovillus from Tigray region was reported. In contrary to these authors work, Hailu [18] reported the highest prevalence of Linognathus spp (75.5\%) and B. ovis $(67.1 \%)$ in sheep from Asella even which disagrees with the present work. This difference in prevalence could be attributed to the effects of climate change and other factor such as changes in animal management and husbandry system practices, usage of acaricides and increase in animal trafficking or movements may also contribute to the changes in the prevalence, or emergence, of lice infestation in certain localities [43].

The current study established that almost closer prevalence of mange mites in both sex groups of sheep, an overall prevalence of $6.06 \%$ was observed in female while $5.75 \%$ mange mite infestation was recorded in the male sheep, and the covariate (sex) was negatively associated $(p>0.05)$ with the prevalence of mange mite infestation. This finding was in agreement with previous observation made by Yacob et al. [10], Zeryehun and Tadesse [33], and Kassaye and Kebede [44] that revealed as sex has no significant effect on the prevalence of mange mites infestation. In addition to this, almost closer prevalence of lice infestation in both male (55.39\%) and female (54.95\%) sheep was observed in this study though there is no significant association between the lice infestation and sexes of the animal.

This study revealed as age group was insignificantly associated with mange mite's infestation. Though there was a negative association between the covariate (age) and mange mite infestation, there was a relatively higher prevalence in adult than young sheep which contradicts the work of Sheferaw et al. [40], and Kassaye and Kebede [44] who reported higher prevalence of mange mite infestation in young age group. Furthermore, age was reported to have no significant effect on the prevalence of mange mites [10].

Like that of mange mite, adult age group of sheep (52.44\%) had a risk of acquiring higher lice infestation than younger sheep $(43.90 \%)$ and the covariate (age) was positively associated $(p<0.05)$ with lice infestation in the present work. This finding is inconsistent with the study of Kassaye and Kebede [44] whom their report revealed that lice infestation was higher in young than in adult animals in Tigray region. The observation of significantly higher prevalence of lice in adult sheep attributed to maternal grooming and separate house that could be reducing exposure in younger animals [38].

The prevalence of lice in poor, medium and good body condition score was $67.36 \%, 46.5 \%$ and $19.12 \%$, respectively in the present study. Significant association $(\mathrm{p}<0.05)$ between the prevalence of lice infestation were evidenced by body condition score, showing a greater susceptibility of animals with poor body condition. However, lower prevalence of lice infestation was reported by Israel et al. [39] whom their finding revealed that $6.5 \%, 5.7 \%$ and $8.3 \%$ in poor, medium and good body condition, respectively in Sodo Zuria district of Southern Ethiopia. Observations that animals with poor body condition score had higher ectoparasite infestation rate suggest negative effect on productivity. Ectoparasites induce itching or worry (reduce time on grazing) and suck blood (compete for nutrients), both of which compromise the nutritional status of host animals [45].

\section{Conclusion}

This study established mange mite and lice infestation in sheep in 
Asella town and its surroundings. A higher prevalence of pediculosis was observed compared to mange mite infestation which was rarely observed with lower prevalence rate. Mange mites genera identified in this study were Sarcoptes, Psoroptes and Chorioptes while no Demodex was identified in the study settings of sheep. With regard to lice infestation, $B$. ovis and $L$. ovillus were the only identified species of lice. The study also revealed that lice infestation was positively associated with the two covariates (age and body condition score) while a negative association was observed between the sex groups. Nonetheless, mange mite infestation was negatively associated with all the risk factors considered in this study. This study disclosed that the poor quality of husbandry practices and/or inadequate veterinary care given to sheep by their owner's. Therefore, the growing threat of mange mite and lice infestation to sheep flock in the study settings requires a well-coordinated control intervention.

\section{References}

1. Tadesse $H$ (2005) Pre-slaughter defects of hides/skin and intervention options in east Africa: Harnessing the leather industry to benefit the poor. In: Regional Workshop Proceedings, April, pp: 18-20.

2. MOA (2010) Ministry of Agriculture: Annual Report on Livestock Production, MOA, Addis Ababa, Ethiopia.

3. Seyoum Z, Tadesse T, Addisu A (2015) Ectoparasites Prevalence in Small Ruminants in and around Sekela, Amhara Regional State, Northwest Ethiopia. J Vet Med 2015: 216085

4. CSA (2008) Agricultural sample survey. Volume II, Report on livestock and livestock characteristics. Volume II, 2007/08, Addis Ababa, Ethiopia.

5. Kumsa BE, Mekonnen S (2011) Ixodid ticks, fleas and lice infesting dogs and cats in Hawassa, southern Ethiopia. Onderstepoort J Vet Res 78: 1-8.

6. Kumsa B, Tamrat H, Tadesse G, Aklilu N, Cassini R (2012) Prevalence and species composition of ixodid ticks infesting horses in three agroecologies in central Oromia, Ethiopia. Trop Anim Health Prod 44: 119-124.

7. Kumsa B, Beyecha K, Geloye M (2012) Ectoparasites of sheep in three agroecological zones in central Oromia, Ethiopia. Onderstepoort J Vet Res 79 $1-7$

8. Kassa B (2006) Cockle, mange and pox: Major threats to the leather industry in Ethiopia. Ethiopian leather industry: Perseverance towards value addition. In: Proceedings of the National Workshop, Addis Ababa, Ethiopia, Pp: 71-92.

9. Berhanu W, Negussie H, Alemu S, Mazengia H (2011) Assessment on major factors that cause skin rejection at Modjo export tannery, Ethiopia. Trop Anim Health Production 43: 989-993.

10. Yacob HT, Nesanet B, Dinka A (2008) Part II: Prevalences of major skin diseases in cattle, sheep and goats at Adama Veterinary Clinic, Oromia regional state, Ethiopia. Rev Med Vet-Toulouse 159: 455-461.

11. Mulugeta $Y$, Yacob HT, Ashenafi H (2010) Ectoparasites of small ruminants in three selected agro-ecological sites of Tigray Region, Ethiopia. Trop Anim Health Prod 42: 1219-1224.

12. Fekadu A, Tolossa YH, Ashenafi H (2013) Ectoparasitesof Small Ruminants in Three Agro-Ecological Districts of Southern Ethiopia. Afr J Basic Appl Sci 5: $47-54$

13. Tolossa YH (2014) Ectoparasitism: Threat to Ethiopian small ruminant population and tanning industry. J Vet Med Anim Health 6: 25-33.

14. Yacob HT, Yalew TA, Dinka AA (2008) Part I: Ectoparasite prevalences in sheep and in goats in and around Wolaita Soddo, Southern Ethiopia. Revue de Méd Vét 159: 450-454

15. Kedir M (2000) Study on mange mite infestations in small ruminants and came in to selected Agro climatic zones in Tigray, Northern Ethiopia. DVM Thesis, Addis Ababa University, Faculty of Veterinary Medicine, Debre Zeit, Ethiopia.

16. Sertse T, Wossene A (2007) A study on ectoparasites of sheep and goats in eastern part of Amhara region, northeast Ethiopia. Small Ruminant Res 69 : $62-67$.

17. Sertse T, Wossene A (2007) Effect of ectoparasites on quality of pickled skins and their impact on the tanning industries in Amhara regional state, Ethiopia. Small Ruminant Res 69: 55-61.

18. Hailu W (2010) Study on the prevalence of major ectoparasites of sheep and assess the major risk factors in Arsi zone of Oromia regional state and evaluate the in vitro and in vivo acaricidal efficacy of seven medicinal plants against lice in naturally infested sheep (Doctoral dissertation, MSc thesis, Addis ababa University, FVM).

19. TDAO (2006) Tiyo District Agricultural Office, Asella.

20. Teklehaimanot D, Gangwar SK (2011) Seroprevalence study of bovine brucellosis in Assela government dairy farm of Oromia regional state, Ethiopia. Int J Sci Nature 2: 692-697.

21. Geresu MA, Ameni G, Tuli G, Arenas A, Kassa GM (2016) Seropositivity and risk factors for Brucella in dairy cows in Asella and Bishoftu towns, Oromia Regional State, Ethiopia. Afr J Microbiol Res 10: 203-213.

22. Steele M (1996) Goats, The Tropical Agriculturalist Series, Macmillan, London UK; CTA Education, Wageningen, The Netherlands.

23. Sheep E (2009) Goat Productivity Improvement Program (ESGPIP) Common defects of sheep and goat skins in Ethiopia and their causes. ESGPIP. Technical Bulletin 19: 1-14

24. Thrusfield M (2007) Sample size determination. In: Veterinary Epidemiology 3rd edn. Blackwell Science Limited, Oxford, UK, Pp: 185-189.

25. Taylor MA, Coop RL, Wall RL (1996) Veterinary Parasitology. 4th edn Blackwell Science, Glasgow, Scotland.

26. Wall R, Shearer D (2001) Veterinary Ectoparasites: Biology, Pathology and Control. 2nd edn. Blackwell Science Ltd., UK.

27. Teshome W (2002) Study on skin diseases of small ruminant in sidama zone Southern Ethiopia. DVM Thesis, Addis Ababa University, Debre Zeit.

28. Mulugeta $Y$ (2008) A study on ectoparasites of small ruminants in selected sites of Tigray regional state and their impact on the tanning industry. Doctoral dissertation, MSc thesis, Faculty of Veterinary Medicine, Addis Ababa University, Debre Zeit, Ethiopia.

29. Mohammed Y, Ali $H$ (2006) Prevalence of ectoparasites of sheep and goat flock in Urmia Subrub, Iran. Vet Parasit 76: 431-442.

30. Rahbari S, Nabian S, Bahonar AR (2009) Some observations on sheep sarcoptic mange in Tehran province, Iran. Trop Anim Health Prod 41: 397-401.

31. Molu N (2002) Epidemiological study on skin disease of small ruminants. DVM Thesis, Faculty of Veterinary Medicine, Addis Ababa University, Debre Zeit, Ethiopia.

32. Takele G (1986) Epidemiological study of small ruminant mange mites in Harrarghe region. DVM Thesis, Faculty of Veterinary Medicine, Addis Ababa University, Debre Zeit, Ethiopia.

33. Zeryehun T, Tadesse M (2012) Prevalence of mange mite on small Ruminants at Nekemte veterinary clinic, East wollega zone, Northwest Ethiopia. Middle East J Sci Res 11: 1411-1416.

34. Mekonnen S, Hussein I, Bedane B (2001) The distribution of ixodid ticks (Acari: Ixodidae) in central Ethiopia. The Onderstepoort J Vet Res 68: 243-251.

35. Mekonnen S, Pegram RG, Gebre S, Mekonnen A, Jobre Y, et al. (2007) A synthesis of ixodid (Acari: Ixodidae) and argasid (Acari: Argasidae) ticks in Ethiopian and their possible roles in disease transmission. Ethiopian Vet $\mathrm{J} 11$ $1-17$.

36. Haffize M (2001) Study on skin diseases of small ruminants in central Ethiopia DVM Thesis, Addis Ababa University, Debre Zeit, Ethiopia.

37. Chalachew N (2001) Study on the skin diseases in cattle, sheep and goats in and around Wolayta Soddo, Southern Ethiopia. DVM Thesis, Addis Ababa University, Facul. Vet. Med. Debre Zeit, Ethiopia.

38. Tefera S (2004) Investigation on ectoparasites in small ruminant in selected sites of Amhara regional state and their impact on the tanning industry. MSc Thesis, Faculty of Veterinary Medicine, Addis Ababa University, Debre Zeit Ethiopia.

39. Israel Y, Abera T, Wakayo BU (2015) Epidemiological study on ectoparasite infestation of small ruminants in Sodo Zuria District, Southern Ethiopia. J Vet Med Anim Health 7: 140-144.

40. Sheferaw D, Degefu H, Banteyirgu D (2010) Epidemiological study of small 
Citation: Deferes D, Geresu MA (2016) Sheep Mange Mites and Lice: Prevalence and Risk Factors in Asella and its Surroundings, South Eastern Ethiopia. J Vet Sci Technol 7: 371. doi: 10.4172/2157-7579.1000371

Page 6 of 6

ruminant mange mites in three agro-ecological zones of Wolaita, Southern Ethiopia. Ethiopian Vet J 14: 31-38.

41. Numery A (2001) Prevalence and effect of ectoparasites in goats and fresh goat pelts and assessment of wet-blue skin defects at Kombolcha Tannery, South Wollo. DVM Thesis, Addis Ababa University, Debre Zeit.

42. Mullen GR, Durden LA (1995) Medical and Veterinary entomology. 2nd edn. CAB International, USA, $\mathrm{Pp:}$ 387-420

43. Shibeshi B, Bogale B, Chanie M (2013) Ectoparasite of Small Ruminants in
Guto-Gidda District, East Wollega, Western Ethiopia. Acta Parasitologica Globalis 4: 86-91.

44. Kassayeq E, Kebede E (2010) Epidemiological study on manage mite, lice and sheep keds of small ruminants in tigray region, northern Ethiopia. Ethiopian Vet J 14: 51-66.

45. Radostits OM, Gay CC, Hinchcliff KW, Constable PD (2007) Veterinary Medicine: A text book of diseases of cattle, sheep, pigs, goats and horses. 10th edn. Saunders, Edinburgh, London. pp: 1585-1612. 